\title{
PEMUJAAN HARITI DI TROWULAN
}

\section{Edi Triharyantoro}

Keywords: iconography; hindu; deities; trowulan; majapahit; statue

\section{How to Cite:}

Triharyantoro, E. (1988). PEMUJAAN HARITI DI TROWULAN. Berkala Arkeologi, 9(1), 17-26. https:// doi.org/10.30883/jba.v9i1.495

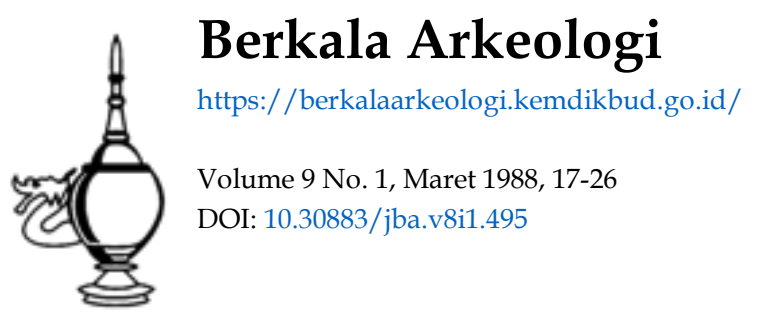




\section{PEMUJAAN HARITI DI TROWULAN}

\section{Edi Triharyantoro}

Dalam Ilmu Arkeologi, agama merupakan salah satu unsur kebudayaan dan dipelajari sebagai sebuah katogeri insani yang bersifat homo symbollicus. Kegiatan batin dan penghasilan lahir dari manusia dalam menanggapi agama sebagai totalitas (fasal-fasal, moral serta intensitas pemujaan), pada hakekatnya adalah usaha manusia tersebut untuk mencapai proses integrasi seutuh-utuhnya dengan kekuatan super natural yang dipujanya.

Usaha ke arah pengintegrasian itulah yang melahirkan simbolsimbol keagamaan sebagai akibat dari perilaku atau pengalamanpengalaman keagamaan (Nurhadi Magetsari, 1977: 500). Intensitas pemujaan terhadap simbol-simbol keagamaan, menampilkan keterkaitan yang sangat besar kepada unsur-unsur utama dari simbol itu sendiri. Pada arca sebagai suatu simbol, prinsip-prinsip seperti bentuk mudrã, ãsana, stãnaka, bahkan wahana, semuanya jelas menunjukkan keterkaitan di atas.

Tidak berbeda dengan agama Hindu, agama Budha juga merupakan suatu agama universal yang menghendaki kekayaan simbol, sekalipun tidak semua simbol mempunyai kadar kekayaan makna yang sama. Hal itu tentu saja tergantung dari kekuasaan dan kemampuan simbol tersebut dalam menghilangkan pengaruh negatif yang dapat menggoncangkan alam semesta. Menjaga kestabilan akan kesuburan adalah salah satu cara untuk mengharmonisasikan alam semesta tersebut. Dalam agama Budha, manifestasi simbol yang menguasai kesuburan berujud figur dewi yang dalam setiap penggambarannya hampir selalu disertai oleh anak-anak pengikutnya, terkenal dengan sebutan dewi Hariti. Selain dianggap sebagai dewi Kesuburan, Hariti juga dianggap sebagai dewi Ibu atau juga 
mendapat julukan dewi Pemberi Kekayaan (Gupte, 1972: 119; Getty, 1962: 86).

Dalam kesempatan ini akan dibicarakan mengenai pemujaan Hariti di kawasan Trowulan. Pendekatan masalah ini tentu saja didukung dengan data arkeologis berupa arca Hariti koleksi museum Trowulan dan koleksi museum Mojokerto dalam perbandingan. Hal ini menarik untuk dikemukakan karena selama ini karya-karya ilmiah arkeologis tentang pemujaan pantheon dewa masih terbatas pada dewa-dewa yang mempunyai kedudukan tinggi (mayor deities), sedangkan untuk dewa-dewa rendah (minor deities) masih sedikit dibicarakan.

\section{II}

Di museum Trowulan yang baru (dekat Segaran), khususnya di ruang pendopo, terdapat koleksi arca Hariti yang dibuat dari terakota. Arca tersebut ada tiga buah, namun dalam kesempatan ini hanya dua buah yang akan diambil sebagai sampel, yaitu arca Hariti dengan nomer inventaris $112 / \mathrm{Tr}^{\prime} \mathrm{ONB} / 24 / \mathrm{BPP}$ dan $113 / \mathrm{Tr} / \mathrm{KPT} /$ 24/BPP.

Arca Hariti nomer 112/Tr/ONB/24/BPP tidak diketahui asalusulnya. Tinggi arca adalah $36,3 \mathrm{~cm}$, dengan lebar $19,6 \mathrm{~cm}$. Keadaan arca pada bagian kepala, tangan kiri sebatas lengan dan sepasang payudaranya telah putus. Demikian pula sebagian anakanak pengikutnya ada yang aus. Hariti digambarkan dalam posisi duduk bersimpuh di atas landasan bulat ganda. Tangan kanan terjurai ke bawah memegang tangan salah satu anak pengikutnya. Anaknya yang lain digambarkan menempel pada paha kanan dan kiri Hariti, namun yang menempel di paha kiri hanya tersisa bagian tangannya saja karena aus. Hariti memakai perhiasan hãra motif tampar dan kañkana. Secara simbolis, anak-anak pengikut itu seolaholah memang digambarkan sebagai hasil tangkapan Hariti. 
Arca dengan nomer $113 / \mathrm{Tr} / \mathrm{KPT} / 24 / \mathrm{BPP}$ ditemukan di dusun Kepiting, desa Temon, kecamatan Trowulan, kabupaten Mojokerto. Ukuran tinggi arca adalah $38,4 \mathrm{~cm}$, dengan lebar $20,3 \mathrm{~cm}$. Keadaan arca hampir sama dengan arca nomer 112 di atas, yaitu bagian kepala, kedua tangan serta sebelah payudaranya telah putus. Hariti digambarkan dengan posisi duduk bersimpuh, memakai wastra dan hãra. Payudara, perut serta pinggulnya digambarkan dalam ukuran serba besar dan ditonjol-tonjolkan (gigantesk). Anak-anak pengikutnya menempel pada bagian paha kanan, kiri, serta pada bagian pinggulnya.

Arca Hariti museum Mojokerto bernomer inventaris 643, berasal dari kawasan Jawa Timur tanpa diketahui persis lokasinya. Dibuat dari batu andesit dan keadaannya masih baik, hanya stela bagian atasnya telah rumpil. Ukurannya hampir dua kali lipat arca terakota Hariti Trowulan. Hariti Mojokerto ini berwajah sumya dengan siraścakra berbentuk bulat menambah kewibawaannya sebagai dewi. Posisi berdiri dengan sikap samabhanga di atas landasan padma ganda. Kedua tangannya sangat mesra menggendong dan menggandeng anak-anak pengikutnya. Payudaranya berukuran normal, namun dalam hal ini digambarkan memakai pakaian kebesaran. Mahkota berbentuk jata makuta, memakai kundala, hãra, keyura, kankana, kucabandha, udarabandha, diakhiri dengan wastra tipis berlipat-lipat menutup sampai pergelangan kaki.

Dari paparan perian di atas, dapat diketahui adanya perbedaan ekspresi simbol antara arca Hariti Trowulan dengan arca Hariti di museum Mojokerto. Di satu pihak arca Hariti Trowulan méengekspresikan suasana keras dan penuh kedahsyatan, di lain pihak arca Hariti museum Mojokerto mengisyaratkan suatu kedamaian total dan sarat dengan pernyataan cinta kasih. 


\section{III}

Pemujaan terhadap sesuatu yang berhubungan dengan masalah kesuburan telah dikenal sejak jaman Batu Tua Akhir (Upper Paleolithic) di daerah Eropa Timur dan Tengah (Hariani Santiko, 1977: 58). Sebab utama munculnya pemujaan terhadap kesuburan, yang pada waktu itu dihubungkan dengan pemujaan terhadap Dewi Ibu, berawal dari perasaan takjub, heran, dan ketidakpahaman manusia akan proses-proses alam, misalnya adalah rahasia kelahiran, baik raha sia kelahiran manusia maupun binatang. Sehubungan dengan jalan pemikiran mereka yang masih sederhana, maka pencarian terhadap sebabsebab itu juga bersifat sederhana. Tokoh Ibulah yang diangesap sebagai sumber penyebabnya, karena berhubungan dengan peryalaman mereka bahwa wanita atau tokoh ibu yang selalu melahirkan.

Upacara kesuburan masa itu dilaksanakan terutam kalau mereka akan pergi berburu, agar jumlah binatang buruanny berlipat ganda. Untuk keperluan upacara tersebut dibuatlah putuns wanita kecil-kecil dari batu, tulang, tanduk rusa atau gading yang semuanya itu dikenal dengan sebutan Venus. Bentuk venu but memiliki ciri-ciri atau simbol-simbol kesuburan (pinggul, na dara) yang sangat berlebihan ukurannya, seringkali berleituk wing hamil, karena yang dipentingkan adalah unsur kesuburannya (Hari. ani Santiko, 1977: 59).

Ketika manusia mulai bercocok tanam, pemujaan terhadap dewi Ibu atau dewi Kesuburan ini menjadi semakin penting. Dewi Ibu dianggap sebagai personifikasi dari tanah yang melahirkan tanamantanaman yang dibutuhkan oleh manusia. Dengan demikian, dewi Ibu pada masyarakat agraris ini selain dianggap sebagai dewi Kesuburan dan juga sebagai dewi Tanah. Anggapan demikian ini muncul karena para petani pada waktu itu percaya bahwa diri mereka itu adalah sebagian dari ciptaan dewa-dewa dan mereka juga percaya bahwa wanita itu selalu berhubungan dengan tanah (Eliade, 1961: 165-166). 
Pemujaan terhadap dewi lbu atau dewi Kesuburan ini berkembang terus sampai periode berikutnya, yaitu sampai dipeluknya agama Hindu dan Budha. Di dalam agama Budha, dikenal dewi yang berhubungan dengan masalah kesuburan, yaitu dewi Mahapratisara dan dewi Hariti. Dewi Mahapratisara adalah salah satu dari lima dewi pelindung dalam agama Budha. Dewi ini dipuja pada setiap musim hujan, dengan tujuan agar masyarakat mendapatkan hasil yang berlimpah pada waktu panen. Selain itu, dewi Mahapratisara juga dianggap dapat memberikan keselamatan bagi kaum wanita yang sedang melahirkan (Bhattacharya, 1978: 69). Sedangkan dewi Hariti mula pertama dianggap sebagai dewi Kesuburan, seperti yang diceritakan dalam suatu mitologi Budhist. Pada mulanya Hariti adalah seorang yakshi yang mempunyai penyakit cacar dan sering memakan anak-anak, tetapi oleh Budha kemudian diubah hidupnya dan ditasbihkan sebagai pemimpin dewi Kesuburan dan dewi Kelahiran Anakanak. (Sahai, 1975: 253-254). Cerita lain tentang Hariti adalah saudara perempuan yaksha Satagiri. Nama atau kata Hariti berarti "pencuri anak-anak", dengan nama lain Abhirati. Dia senang berpesta dan makan daging anak-anak di Rajagriha. Selanjutnya diceritakan bahwa rakyat Rajagriha sangat bersedih karena olah Hariti tersebut, tetapi kemudian mereka mendekati Budha supaya melindungi anak-anaknya. Budha kemudian membawa Priyankhara, anak termuda dari Hariti ke tempat yang sangat jauh. Hariti mencari sampai ke pelosok dunia tanpa hasil, akhirnya dia datang kepada Sang Budha untuk minta pengembalian anaknya. Budha mau mengembalikan anak tersebut jika Hariti bertobat dan bersedia mengikuti ajaran-ajarannya. Akhirnya Hariti mau menjadi pemeluk agama Budha dan dikenal sebagai dewi Ibu dan dewi Kesuburan (Gupte, 1972: 119).

Pemujaan terhadap Hariti sebagai dewi Kesuburan terdapat di beberapa daerah di dunia. Selain di India, Hariti juga dikenal di Tibet. Cina dan Jepang. Di India, Hariti dapat dijumpai di British Museum atau di Gandara. Di British Museum Hariti digambarkan dalam posisi duduk dengan sikap pralambapãdãsana di atas singga- 
sana. salah satu anaknya digambarkan santai dalam pelukannya sambil tangannya memainkan kalung Hariti. Anak-anak yang lain ada yang bergelut, memakan buah dalam posisi mendekam. Sedang Hariti di Gandara digambarkan dengan payudara berukuran besar. Sebagai suatu catatan penting perlu dikemukakan bahwa pada waktu diadakan ekskavasi di situ Chirand. distrik Bihar, di musim semi 1964, telah ditemukan sebuah arca Hariti dari terakota. Arca ini digambarkan sedang memeluk salah satu anaknya (Gupte. 1972: 254-256).

Di dalam manuskrip yang diketemukan di Tibet, digambarkan bahwa Hariti berwarna merah, dengan salah satu tangannya membawa nakula. Selain itu juga terdapat Hariti yang digambarkan bertangan duả, tangan kanan bersikap Varadamudrã, sedang tangan kiri memegang mangkuk permata. Di sebelah kirinya terdapat nakula dan anak kecil yang menempel di paha kanannya (Getty, 1962: 86).

Di Cina Hariti sangat terkenal pada periode dinasti Tang dan mempunyai nama lain yaitu Kui-pu-mu-shen. Tujuan pemujaan terhadapnya ialah untuk menghindarkan diri dari serangan penyakit (Getty, 1962: 86).

Sedang di Jepang, Hariti dipuja baik dalam kedudukannya sebagai dewi maupun sebagai yakshi. Sebagai dewi ia bernama Koyasu-Kwan-non, sedang sebagai yakshi bernama Kishi-mo-jin. Kedua perwujudan Hariti ini digambarkan bersama-sama dengan sejumlah anak-anaknya, namun demikian tak ada satupun dalam pelukannya (Getty, 1962: 86).

Di Indonesia, pemujaan Hariti dikenal di Jawa Tengah dan Bali. Di Jawa Tengah Hariti digambarkan berupa relief pada dinding lorong pintu masuk candi Mendut dan Banyunibo. Hariti di dua candi ini digambarkan dalam posisi duduk dengan sejumlah anakanaknya yang bermain-main, sedang dinding lorong di depannya dipahatkan Kuwera sebagai dewa Kekayaan yang menjadi suaminya (Edi Triharyantoro, 1985: 14-22). Hariti di Bali dapat dijumpai di Goa Gajah dekat Bedulu. Digambarkan bersama-sama dengan ketiga 
anaknya, yang berada di kanan. kiri dan di pangkuannya (Bernet Kempers, 1960: 43). Dalam cerita rakyat Bali, dewi Hariti sebagai dewi Kesuburan disebut dengan nama lain, yaitu Men Brayut (Stutterheim, 1935: 35; Bernet Kempers, 1977: 130).

\section{IV}

Dari uraian di atas, dengan beberapa keseragaman dan sedikit perbedaan manifestasi simbol Hariti sebagai dewi Kesuburan, maka dapat diasumsikan bahwa pemujaan terhadapnya adalah bersifat universal. Dengan demikian dapat ditafsirkan bahwa daerah-daerah yang mengenal pemujaan terhadap Hariti, paling tidak berhubungan dengan unsur-unsur kesuburan itu sendiri, dalam hal ini adalah soal air dan seluk beluk pertanian.

Sudah menjadi kesepakatan para ahli bahwa Trowulan adalah bekas ibukota Majapahit. A.S. Wibowo pernah mencoba mendekati permasalahan dari dua jalur, yaitu dengan menguraikan sejarah penelitian di Trowulan dan berusaha menerangkan identitas Trowulan dari sudut philology. Namun demikian di akhir tulisannya masih belum didapatkan suatu asumsi yang mengatakan bahwa daerah Trowulan adalah bekas ibukota Majapahit (A.S. Wibowo, 1983: 3-15). Baru setelah dikenalnya sistem penginderaan jarak jauh untuk mendeteksi feature-feature di dalam tanah sebagai usaha ke arah rekonstruksi jaringan kanal kuno yang saling potong di situs Trowulan, maka dapat disimpulkan bahwa Trowulan adalah benar sebagai bekas ibu kota Majapahit.

Dari kenyataan di atas dapat dipikírkan bahwa demikian erat kaitannya antara fungsi air sebagai unsur lingkungan dengan dasar pemikiran pendirian lokasi kota kuno. $\mathrm{Di}$ samping itu dapat diketahui bahwa tujuan pembuatan saluran-saluran air, kanal-kanal serta waduk-waduk hampir dapat dipastikan untuk keperluan pertanian (Djoko Dwiyanto, 1984: 22). 
Di daerah Trowulan memang banyak ditemukan kolam buatan yang berfungsi sebagai irigasi. Nama-nama seperti Balong Bunder tepat di selatan Segaran dan Balong Dowo lebih jauh ke Selatan lagi, sudah memberikan informasi yang jelas, sebab keduanya berarti kolam bulat dan kolam panjang. Belum lagi terhitung adanya bekasbekas saluran dan bak kontrol yang oleh penduduk dikira sumur. yang semuanya terbuat dari susunan batu bata. Bahkan di dukuh Blendren, desa Watesumpak (Trowulan sebelah Utara) masih dapat dilihat bekas kolam yang hanya tinggal sudut Tenggaranya. Di sudut ini dapat dijumpai mulut saluran selebar $50 \times 75 \mathrm{~cm}$. Pada musim hujan dari mulut itu keluar air berlimpah yang sanggup mengairi sawah sawah di sekitarnya (A.S. Wibowo, 1977: 42).

Diterapkannya sistem pengairan dalam pengolahan pertanian tersebut menciptakan bagan ekologis yang memperlihatkan suatu interaksi bahkan suatu ketergantungan dari para petani terhadap potensi lahannya. Di lain pihak, para petani terkungkung di dalam relung ekologi rawan yang justru merupakan hasil karya mereka sendiri. Sistem sawah dalam kerangka ekologis merupakan suatu sistem yang diperkhusus (specialized ecosystem). Sedikit saja ketidakseimbangan berlangsung pada relung ekologi yang bersangkutan. penurunan kualitas hidup pada skala sedang akan terjadi (Bugie M.H. Kusumohartono, 1985: 62-63). Untuk mengatasi hal demikian ini, di samping dengan usaha-usaha yang bersifat profan seperti mengembangkan teknologi dan pengetahuannya, mereka juga berusaha dalam semangat sakral, yaitu memuja-muja kekuatan super natural yang dianggap dapat menstabilkan kesuburan.

Dengan demikian jelas dapat disimpulkan bahwa pemujaan ter: hadap dewi Hariti sebagai dewi Kesuburan selain dikenal di Jawa Tengah. Bali, juga dikenal di Jawa Timur. Dilihat dari berituk terakota Hariti dari Trowulan yang menyiratkan simbol kedahsyatan dan keganasan, maka dapat dikatakan bahwa gambaran tersebut adalat manifestasi Hariti dalam statusnya sebagai yakshi. Apakah ini ada hubungannya dengan sifat-sifat Tantris yang masih tersisa di Majapahit? Kiranya memerlukan telaah lebih lanjut. 


\section{KEPUSTAKAAN}

Abu Sidik Wibowo. 1977. "Fungsi kolam-buatan di ibukota Majapahit". Majalah Arkeologi. 11/3. hal. 41-49.

Wibowo, A. (1983). NAGARAKERTAGAMA DAN TROWULAN. Berkala Arkeologi, 4(1), 1-20. https://doi.org/10.30883/jba.v4i1.300

Bernet Kempers A.J. 1960. Bali Purbakala. Djakarta: Penerbit P.T. Penerbit Balai Buku "Ichtiar".

Bernet Kempers A.J., 1977. Monumental Bali. Den Haag: van Goor Zonen.

Bhattacharya, 1978. Studies in Buddhist Iconography. New Delhi: Ashoka Press.

Kusumohartono, B. M. (1985). PENDEKATAN LINGKUNGAN DALAM REKONSTRUKSI PERTUMBUHAN PEMUKIMAN TROWULAN KUNA: SUATU PEMIKIRAN INDUKTIF. Berkala Arkeologi, 6(1), 56-66. https:// doi.org/10.30883/jba.v6i1.436

Dwiyanto, D. (1984). PERANAN JARINGAN AIR PADA KOTA - KOTA KUNA DI ASIA TENGGARA. Berkala Arkeologi, 5(2), 17-35. https:// doi.org/10.30883/jba.v5i2.424

Edi Triharyantoro, 1985. Pemujaan Kuwera Periode Klasik Jawa Tengah (Abad VIII-X) skripsi sarjana. UGM (tidak diterbitkan).

Getty, Alice. 1962. The Gods of Northern Buddhism (Charles E. Tuttle Company Rutland, Vermond \& Tokyo, Japan).

Gupte , R.S. 1972. Iconography of The Hindus Buddhist and Jains. Bombay: DB Taraporevala and Private Ltd.

Hariani Santiko, 1977. "Dewi Sri Unsur Pemujaan Kesuburan pada Mitos Padi", MIS/ VII No. 3 Jakarta, Penerbit Bhratara. hal. 53-67.

Mircea, Eliade, 1961. "The Nature of Religion", The Sacred And The Profane. New York: Harper \& Row Publisher.

Nurhadi Magetsari, 1980. "Kemungkinan Agama Sebagai Alat Pendekatan Dalam Penelitian Arkeologi", Pertemuan llmiah Arkeologi I. Jakarta: Pusat Penelitian Purbakala dan Penggalian Nasional, 1980 . Halaman 498-504.

Stutterheim. W.F. 193. Indian influences in Old Balainese Art London: The India Society. 


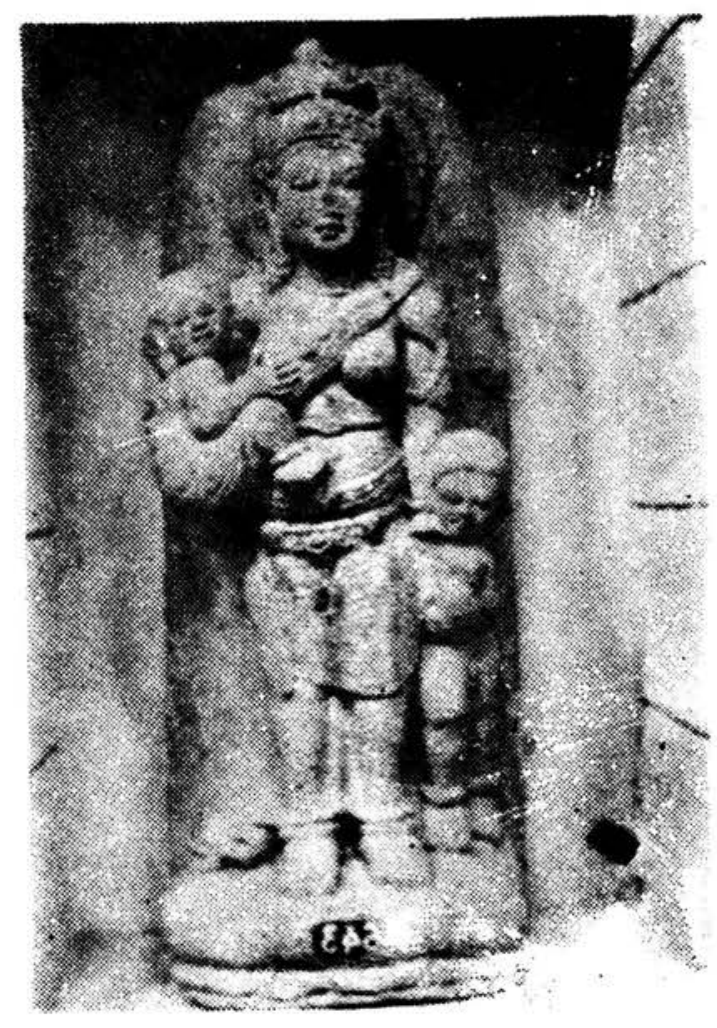

Arca batu Hariti dari Museum Mojokerto.

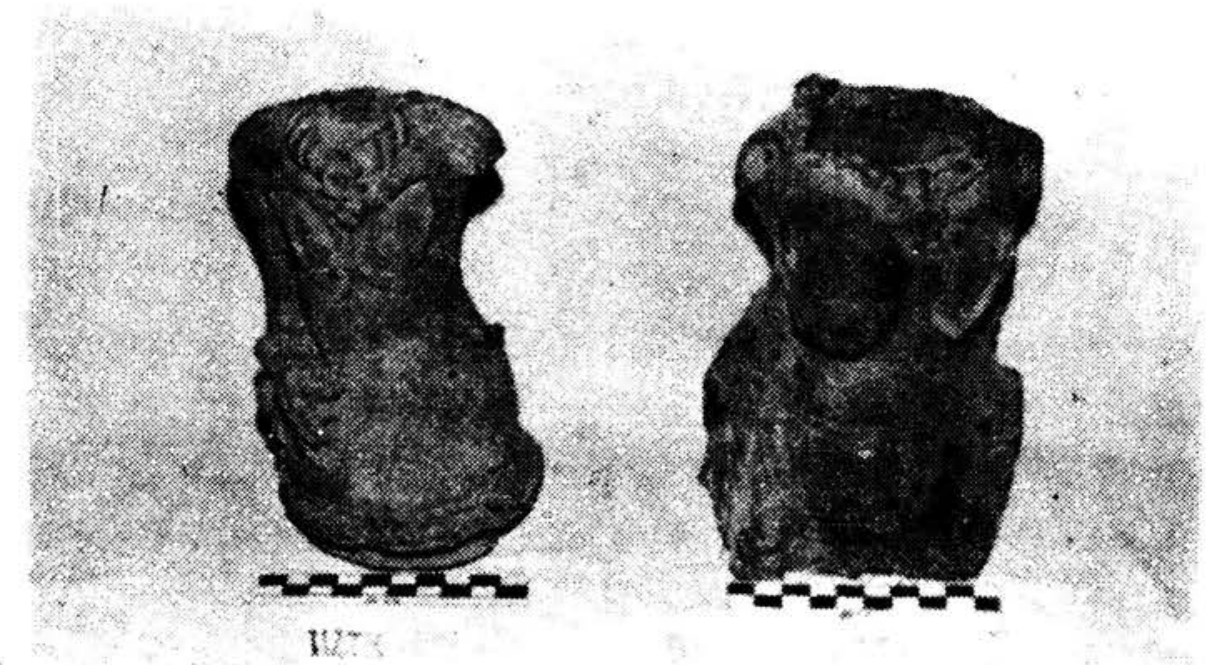

Arca Terakota Hariti dari Museum Trowulan. 